
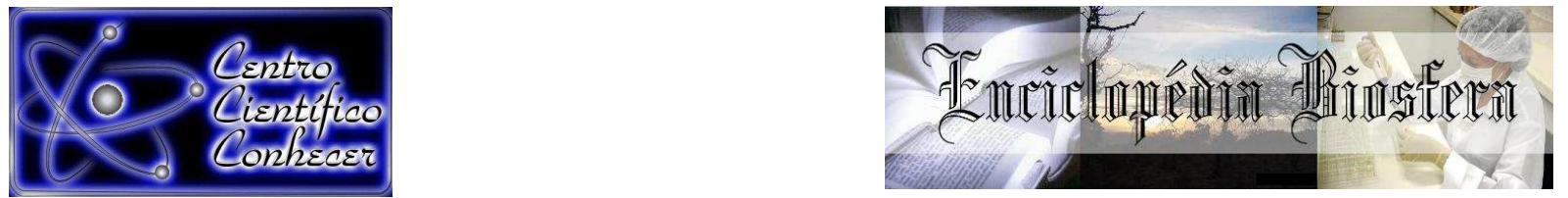

\title{
DETERMINAÇÃO DA PERDA DE PESO DE GRÃOS DE MILHO ARMAZENADOS ATRAVÉS DE DIFERENTES MÉTODOS
}

\author{
Eletisanda das Neves ${ }^{1}$, Roberto Antônio Martinez Savelli ${ }^{2}$ \\ ${ }^{1}$ Professora de Educação Superior/Departamento de Agronomia/Eng. Agrícola, \\ UNEMAT - Câmpus Universitário de Nova Mutum, Nova Mutum, Mato Grosso, \\ Brasil. eletisanda@unemat.br \\ ${ }^{2}$ Professor de Educação Superior/Departamento de Agronomia/Eng. Agrônomo, \\ UNEMAT - Câmpus Universitário de Tangará da Serra, Tangará da Serra, Mato \\ Grosso, Brasil. robertosavelli@hotmail.com
}

Recebido em: 02/10/2017 - Aprovado em: 21/11/2017 - Publicado em: 05/12/2017 DOI: 10.18677/EnciBio_2017B22

\begin{abstract}
RESUMO
A ocorrência de perdas nos grãos após a colheita possui importância significativa para o abastecimento alimentar mundial. A quebra técnica existe na massa de grãos ou sementes armazenadas e diz respeito a perda de peso ao longo do período de armazenamento. Esta perda ocorre devido às reações químicas de oxidação, durante o processo respiratório.Neste contexto, a pesquisa teve como objetivo avaliar o efeito das temperaturas de secagem de grãos de milho em espiga no período de armazenamento em dois tipos de embalagens em condições ambientais não controladas e a utilização de diferentes métodos de determinação da perda de peso e a quebra técnica de grãos de milho em espiga. Utilizou-se a variedade DowAgrocienses com umidade inicial de $26 \%$. Foram utilizadas três combinações de temperaturas do ar de secagem: $40-45^{\circ} \mathrm{C}$; $50-55^{\circ} \mathrm{C}$ e $70-75^{\circ} \mathrm{C}$ e a testemunha foi a secagem ao sol. Foram utilizados alguns métodos para determinação de perda de peso direta ou indireta através dos Métodos propostos por Harris e Lindblad (1978),por Compton et al. (1998), por Bern et al. (2002) e por White et al. (1982).O experimento foi instalado em delineamento casualizado ao acaso, sendo que, para cada embalagem houve quatro tratamentos, constituídos de um ambiente de armazenamento e cinco épocas de amostragem para avaliações, em arranjo fatorial, com três repetições por tratamento e a análise estatística dos dados foi realizada pelo SAEG 5.0. Houve diferença de perdas de peso nas diferentes embalagens e, em dois métodos de determinação da perda nas embalagens de papel e plástico não houve significância.
\end{abstract}

PALAVRAS-CHAVE: Armazenamento, Quebra técnica, Respiração 


\title{
WEIGHT LOSS DETERMINATION OF CORN GRAINS STORED THROUGH DIFFERENT METHODS
}

\begin{abstract}
The occurrence of grain losses after the harvest have a significant importance for the world food supply. The breakdown exists in the mass of grains or seeds stored and relates to weight loss over the storage period. This loss occurs due to chemical oxidation reactions during the respiratory process. In this context, the aim of this research was to evaluate the effect of drying temperatures of corn grains in the storage period in two types of packages under uncontrolled environmental conditions and the use of different methods to determine weight loss and technical breaking of corn on the cob. The Dow Agroscience variety with initial moisture of $26 \%$ was used. Three temperature combinations of drying air were used: $40-45^{\circ} \mathrm{C} ; 50-55^{\circ} \mathrm{C}$ and $70-75^{\circ} \mathrm{C}$ and the control was sun drying. Some methods were used to determine direct or indirect weight loss by the methods proposed by Harris and Lindblad (1978), by Compton et al. (1998), by Bern et al. (2002) and by White et al. (1982). The experiment was set up in a randomized complete design, with four treatments, consisting of a storage environment and five sampling periods for evaluations, in a factorial arrangement, with three replications per treatment and the statistical data analysis was analyzed by the SAEG 5.0. There were differences of weight losses in the different packages and in two methods of determination of the losses in paper and plastic packages there was no significance.
\end{abstract}

KEYWORDS: Storage, Technical breakdown, Breath

\section{INTRODUÇÃO}

A ocorrência de perdas nos grãos e/ou sementes após a colheita possuem importância significativa para o abastecimento alimentar mundial e podem representar entre 5 a $10 \%$ da produção global de grãos de cereais e sementes oleaginosas. Enquanto as maiores perdas resultam de infestações por insetos, microrganismos, roedores e pássaros, uma pequena, mas importante, parte do total de perdas resulta da respiração dos grãos e conseqüente deterioração gradual da viabilidade, da qualidade nutritiva, e das propriedades para uso final, durante a armazenagem, de acordo com Pomeranz (1992).

A quebra técnica existe na massa de grãos ou sementes armazenadas e diz respeito a perda de peso ao longo do período de armazenamento. Esta perda ocorre devido às reações químicas de oxidação, durante o processo respiratório, as quais consomem energias acumuladas sob forma de compostos orgânicos como os açúcares, amidos e outros diminuindo de forma efetiva a massa e, portanto, o peso do produto. Para Cardoso et al. (2012), o processo de deterioração é inevitável, mas pode ser retardado dependendo das condições de armazenamento e das características do grão ou semente.

A liberação de $\mathrm{CO}_{2}$ pelos grãos representa a quebra técnica do produto, sendo que a presença de fungos acelera este processo, ainda mais rapidamente em ambientes úmidos e quentes. A quebra técnica pode ser ocasionada devido a ataque de insetos, pássaros ou roedores; movimentação do produto; tipo de estrutura armazenadora, entre outros fatores. Levando em conta experiências práticas em 
unidades de armazenamento, foi estabelecido, no Brasil, um índice oficial de quebra técnica de 0,15\% por mês de armazenamento (BAUDET; VILLELA, 2000).

Em virtude da necessidade de maiores esclarecimentos em unidades armazenadoras e por não haver uma comprovação científica da ocorrência efetiva da quebra técnica em condições tropicais, a pesquisa teve como objetivo avaliar o efeito das temperaturas de secagem de grãos de milho em espiga no período de armazenamento em dois tipos de embalagens em condições ambientais não controladas e a utilização de diferentes métodos de determinação da perda de peso e a quebra técnica de grãos de milho em espiga.

\section{MATERIAL E MÈTODOS}

Foi utilizado um lote de sementes de milho (Zea mays L.) em espiga, do híbrido triplo, variedade DowAgrocienses com umidade inicial de $26 \%$. Após a colheita, as espigas foram transportadas para um local onde foi procedido o despalhamento manual, a remoção das espigas enfermas e antes de se proceder à secagem foi determinada à umidade inicial e a retirada de amostras do lote de sementes para determinação da qualidade da semente. Após a secagem, foi realizada manualmente a debulha das espigas, para obtenção das amostras de sementes e avaliada a qualidade.

Em relação à temperatura do ar de secagem, foram simuladas as condições de secagem industrial de sementes de milho em espiga, em que, no início do processo, foram empregadas temperaturas mais baixas, geralmente $5^{\circ} \mathrm{C}$ abaixo da temperatura máxima de secagem. Desta forma, em cada uma das diferentes combinações estudadas, foi utilizada a temperatura mais baixa durante 24 horas seguida da temperatura alta pelo tempo necessário para as sementes atingirem $11-12 \%$ de umidade. Foram utilizadas três combinações de temperaturas do ar de secagem: 40$45^{\circ} \mathrm{C} ; 50-55^{\circ} \mathrm{C}$ e $70-75^{\circ} \mathrm{C}$ e a testemunha foi a secagem ao sol.

Quando as sementes atingiram umidade final de $11,68 \%$, a temperatura do ar foi diminuída para $30^{\circ} \mathrm{C} \pm 1^{\circ} \mathrm{C}$ por um período de 12 horas, para pré-resfriamento. A temperatura do ar de secagem foi controlada através de um termostato, colocado na base da câmara do secador estacionário, que foi um modelo de estufa que tem o mesmo princípio do secador estacionário, muito utilizado pelos produtores de sementes de cebola para realizar a secagem das mesmas. Nesse modelo de secador, as sementes foram secadas uniformemente, pois as espigas causam baixa resistência a passagem do ar na camada.

A camada de espigas foi em torno $0,80 \mathrm{~m}$, e as espigas foram distribuídas ao acaso. Após atingir a umidade de 11,68\%, as sementes foram debulhadas manualmente, foram determinadas as umidades finais e a qualidade fisiológica e sanitária das amostras de cada tratamento.

Após a secagem e debulha manual, as amostras de sementes foram acondicionadas em embalagens de papel e plástico com capacidade para $1 \mathrm{~kg}$, sendo mantidas em local arejado, sob condições não controladas, durante dez meses, com realização dos testes de avaliação da qualidade a cada dois meses. As amostras foram colocadas embalagens que foram avaliadas por época constituídas de três repetições, sendo assim, após cada avaliação as mesmas foram descartadas, não sendo reutilizadas. A temperatura e a umidade relativa do ar durante o período de armazenamento, foram monitoradas utilizando-se um psicrômetro instalado próximo às 
sementes. A faixa de temperatura do ambiente atingida foi de $20-32^{\circ} \mathrm{C}$ e a umidade relativa do ar foi de $55-95 \%$.

O experimento foi instalado em delineamento casualizado ao acaso, sendo que, para cada embalagem houve quatro tratamentos, constituídos de um ambiente de armazenamento e cinco épocas de amostragem para avaliações, em arranjo fatorial, com três repetições por tratamento. A análise estatística dos dados foi realizada pelo Software SAEG 5.0. e a comparação das médias dos dados transformados pela fórmula $\sqrt{ } x+1$ foi realizada através do teste de Tukey, ao nível de $5 \%$ de probabilidade.

- A perda de peso foi determinada por diferentes técnicas: direta e indireta

a) Método proposto por Harris e Lindblad (1978), baseado no teste gravimétrico das amostras e pesos de grãos danificadas e não danificadas com três repetições de 100 sementes.

b) Método proposto por Compton et al. (1998), utilizando o teste gravimétrico contando grãos danificadas e pesagem da amostra final e inicial, fazendo-se a correção da umidade dos grãos.

c)Método proposto por Bern et al. (2002) após correções de temperatura do ambiente, umidade e danos causados nas sementes, determinou-se a quantidade de $\mathrm{CO}_{2}$ liberada durante cada período de armazenamento, utilizando a fórmula:

d) Método proposto por White et al. (1982) utilizou-se a equação abaixo para determinar a quantidade de $\mathrm{CO}_{2}$ produzida durante o armazenamento.

\section{RESULTADOS E DISCUSSÃO}

Perdas determinadas de forma direta

Para o teste realizado de perda de peso, os fatores tipo de embalagem, períodos de avaliação e temperaturas de secagem mostraram efeito significativo. Pode-se observar que a perda de peso dos grãos foram mais elevadas no tratamento de secagem realizada ao sol, em todo o período que os grãos ficaram armazenados em embalagem de papel, conforme a Figura 1. Observa-se também, que no período de oito meses a perda de peso foi mais elevada independente do tratamento de secagem utilizado. 


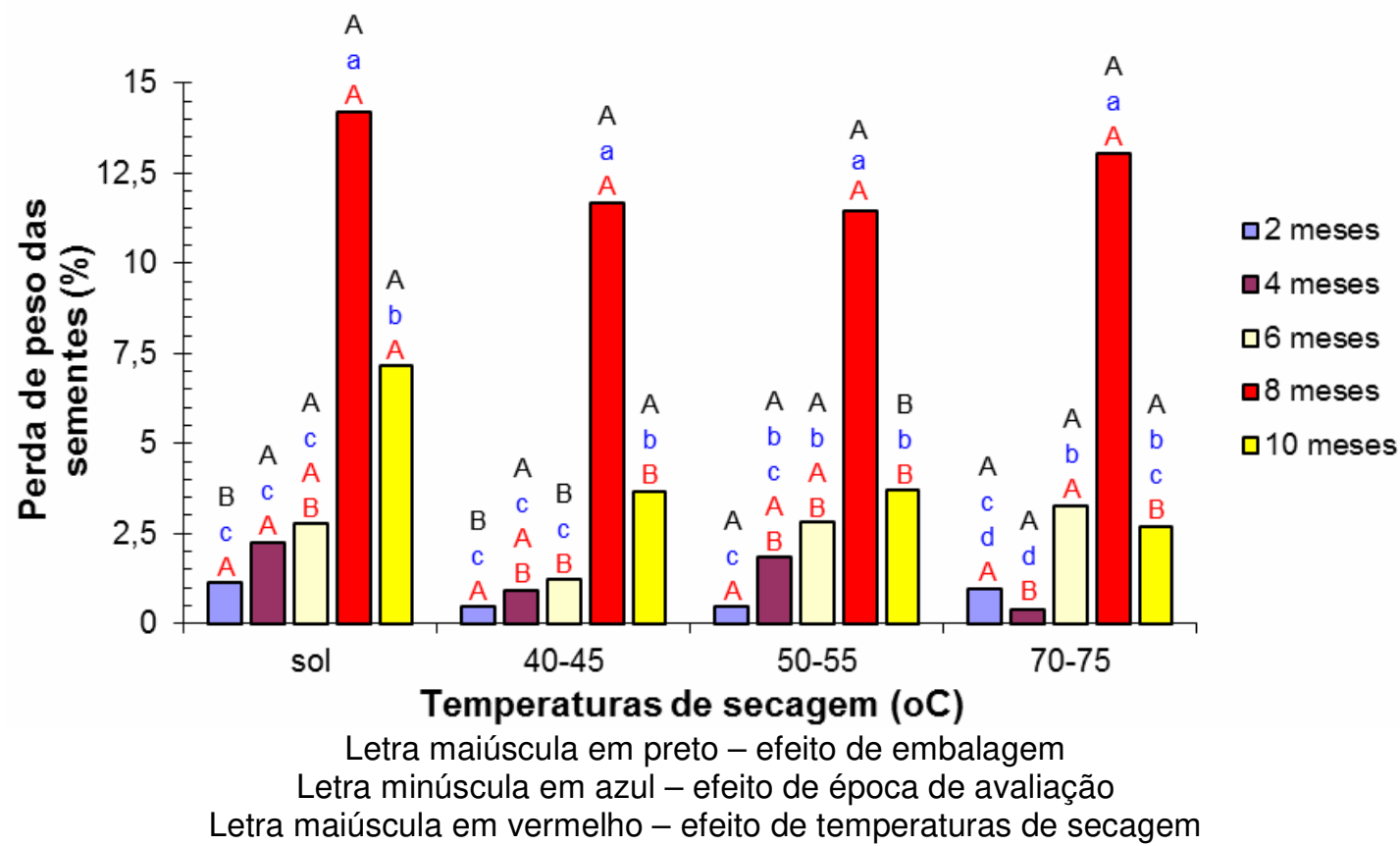

FIGURA 1. Perdas de peso calculadas pelo Compton et al, 1998 em embalagem de papel

Na Figura 2, a perda de peso dos grãos na embalagem de plástico foi um pouco diferenciada da perda ocorrida na embalagem de papel. A interação embalagem $X$ época de avaliação não foi significativa.

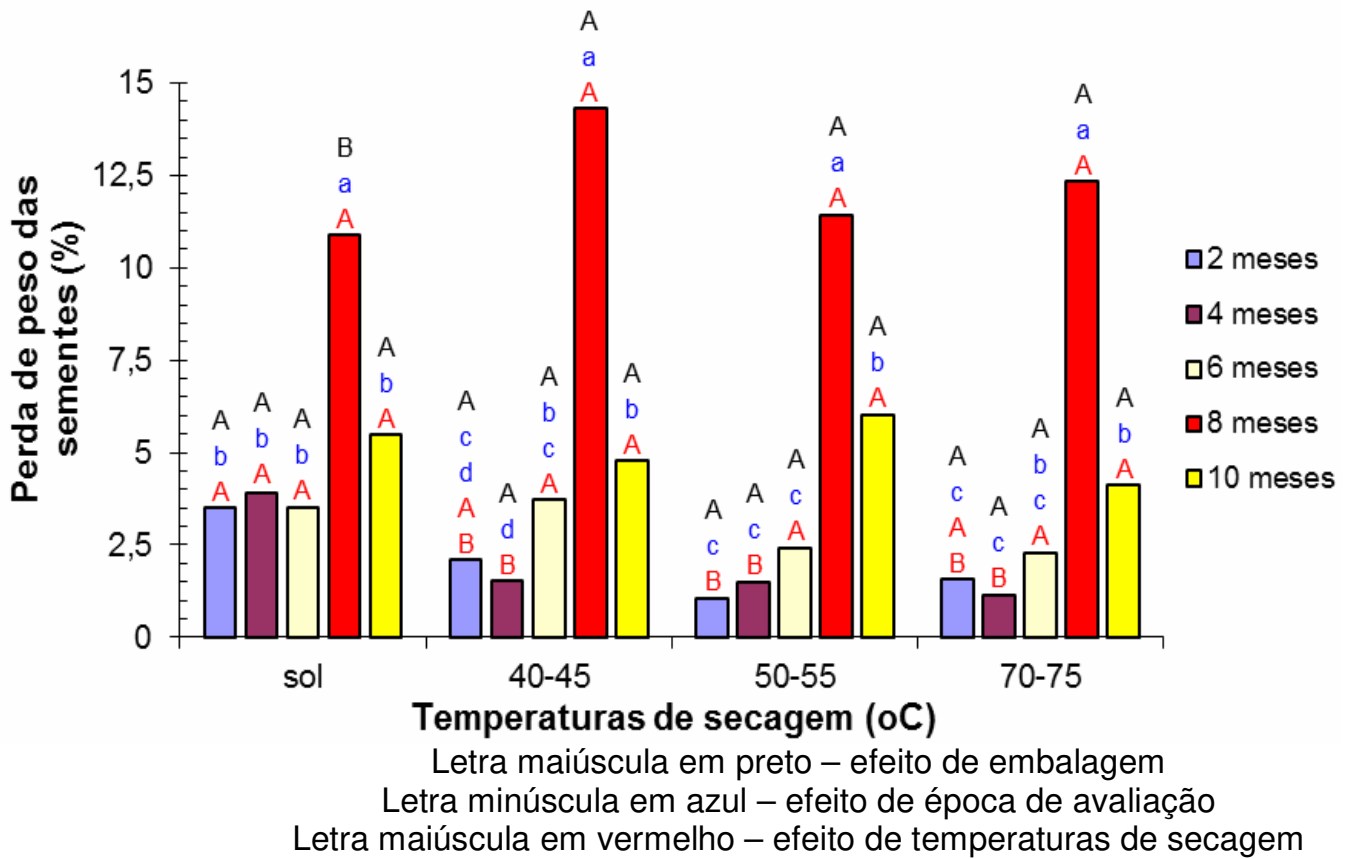

FIGURA 2. Perdas de peso calculadas pelo Compton et al. 1998 em embalagem de plástico 
A perda foi mais elevada no período de dois meses de armazenamento para o tratamento de secagem realizado ao sol. A interação época $X$ temperatura de secagem foi significativa para o método de determinação das perdas. Essa perda mais elevada no período de oito meses de armazenamento nos grãos armazenados tanto em embalagem de papel e plástico, provavelmente pode ter sido ocasionada pelas condições ambientais do local de armazenamento. Nesse período a umidade relativa do ar foi mais elevada em relação à época anterior e posterior, influenciando assim, o teor de água dos grãos que foi em média de $12 \%$ para os grãos armazenados em papel e $11 \%$ para os armazenados em plástico.

As perdas constatadas nas Figuras 1 e 2 determinadas pelo método do Compton et al. (1998) foram superiores a $10 \%$ em oito meses nas diferentes combinações de temperatura de secagem. No entanto, a média de perda no período de dois e seis meses foi em torno de 0,2 a $2,5 \%$ em todos os tratamentos de secagem nos grãos armazenados em papel. Nas embalagens de plástico a perda foi em média de 0,5 a $2,55 \%$ nos tratamentos de secagem de $40-45 ; 50-55$ e $70-75^{\circ} \mathrm{C}$ no mesmo período citado anteriormente. Já no tratamento de secagem ao sol, a perda foi acima de 2,5\%. Por outro lado, as demais verificadas no estudo foram maiores que às encontradas por Santos et al., (2012) que encontrou no seu estudo no armazenamento de grãos de milho durante 150 dias, com teor de água de $17,9 \%$ em temperatura de $35{ }^{\circ} \mathrm{C}$ apresentaram uma perda de matéria seca de 0,037\%.

Observa-se que para o período de quatro meses de armazenamento as médias de perda de peso nas diferentes embalagens não diferem entre si estatísticamente em todos os tratamentos de secagem utilizados. Para o teste realizado de perda de peso, os fatores de temperaturas de secagem e períodos de avaliação mostraram efeito significativo. Já para o fator tipo de embalagem não mostrou significância. Na Figura 3 pode-se observar que a maior perda de peso dos grãos foi constatada no período de quatro meses no tratamento de secagem de $70-75^{\circ} \mathrm{C}$ e em dez meses foram mais elevadas no tratamento de secagem realizado a sol e em 40$45^{\circ} \mathrm{C}$.

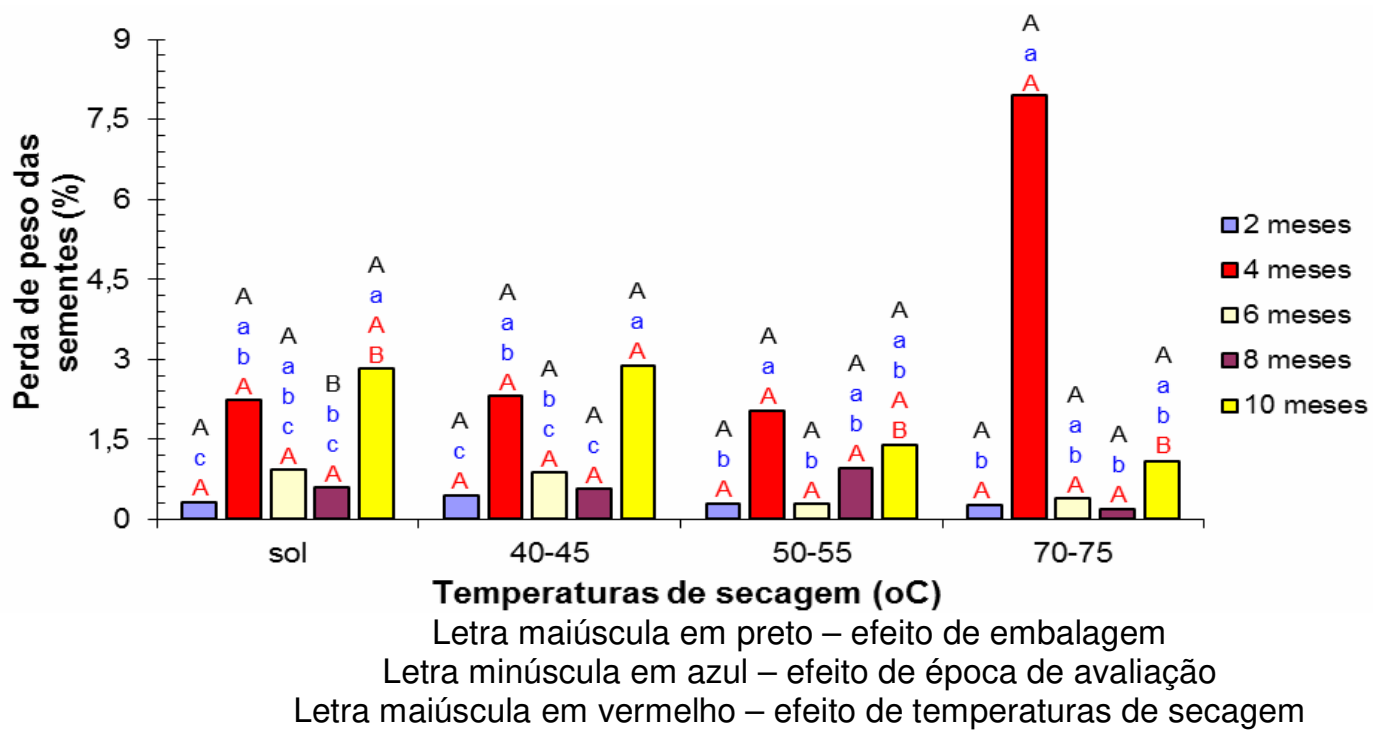

FIGURA 3. Perdas de peso calculadas pelo Harris e Lindblad 1978 em embalagem de papel 
$\mathrm{Na}$ Figura 4, as perdas foram mais elevadas no período de dez meses de armazenamento nos tratamentos de secagem ao sol e em $50-55^{\circ} \mathrm{C}$. Porém, em quatro meses de armazenamento as perdas foram bem elevadas do que nos períodos de dois, seis e oito meses independente do tratamento de secagem nos grãos armazenados em embalagem de plástico. A interação embalagem $X$ época de avaliação e embalagem $X$ temperatura de secagem foram altamente significativas no método de determinação do Harris e Lindblad (1978).

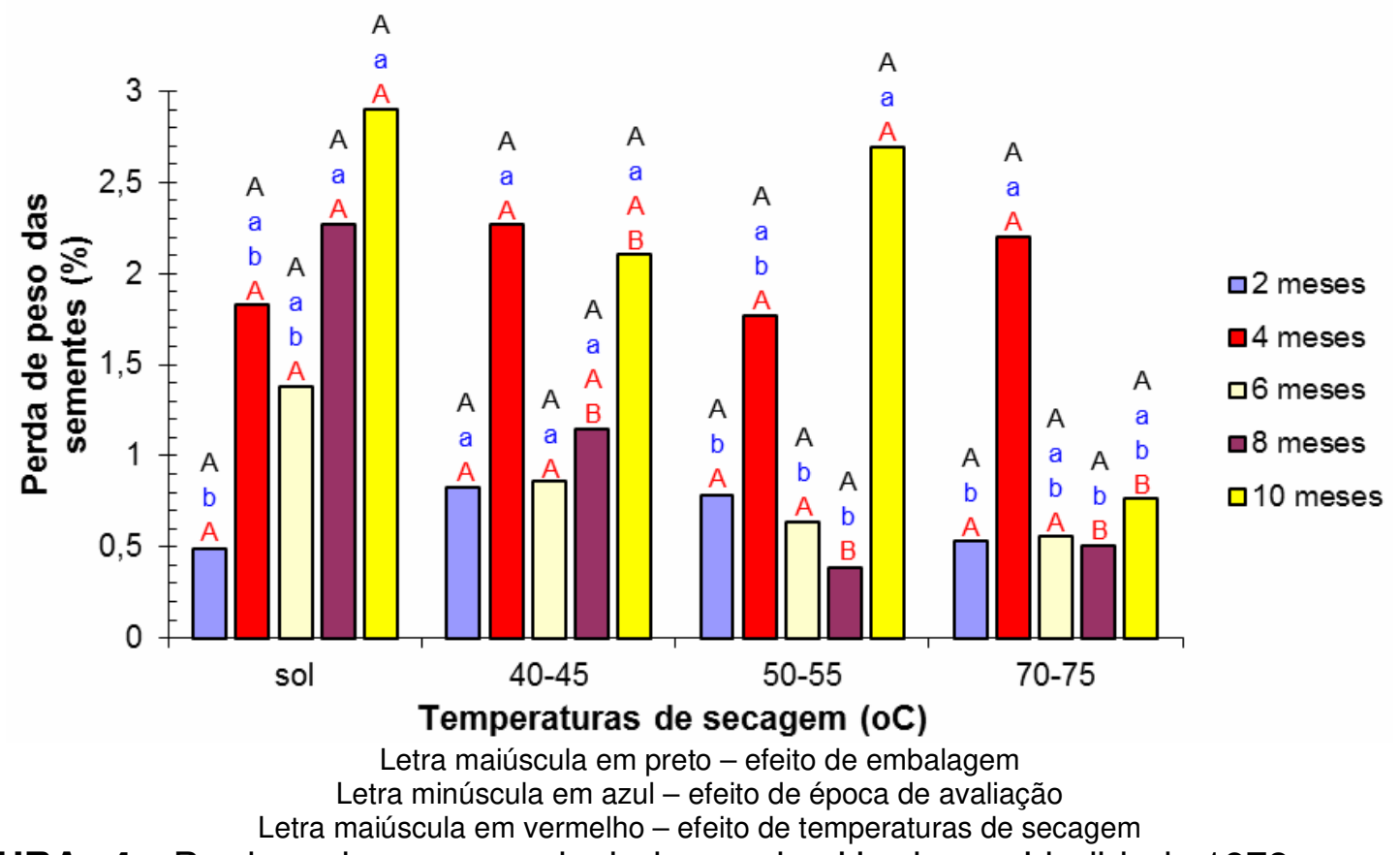

FIGURA 4. Perdas de peso calculadas pelo Harris e Lindblad 1978 em embalagem de plástico

As perdas constatadas nas Figuras 3 e 4 foram superiores em média de $7,5 \%$ no período de quatro meses na combinação de temperatura de $70-75 \%$. No entanto, nos outros períodos em todos os tratamentos de secagem a perda verificada foi em torno de 0,2 a $2,8 \%$ nos grãos armazenados em embalagem de papel. Nas embalagens de plástico a perda foi em média $3 \%$ em 10 meses nos tratamentos de secagem a sol e $50-55^{\circ} \mathrm{C}$.

As perdas encontradas nos dois métodos de determinação nos dois tipos de embalagens foram acima da perda máxima aceitável adotada por Gupta et al. (1998) em grãos de milho danificados, verificando que quando encontrada uma perda de $0,5 \%$ de matéria seca, o milho era de qualidade inaceitável. Por outro lado, os resultados de perdas encontradas no estudo foram menores do que as estimadas e aceitáveis por agricultores que armazenam o milho em seleiros nos EUA, as quais estão entre 5 a $20 \%$ consideradas baixas por eles, conforme (COMPTON ,1992).

Nas Figuras 3 e 4 observa-se que nos períodos de dois, quatro, seis e dez meses de armazenamento as médias de perda de peso nas diferentes embalagens não diferem entre si estatisticamente em todos os tratamentos de secagem utilizados. Já em relação ao efeito do fator época de avaliação nas médias de perda de peso dos grãos 
de milho verificou-se que as médias de perda diferiram significativamente em todo o período de armazenamento.

Observa-se ainda, nas Figuras 3 e 4 houve diferenças significativas nos tratamentos de secagem nas diferentes embalagens, em que no período de oito meses no tratamento de secagem a $70-75^{\circ} \mathrm{C}$ as médias diferem significativamente com valor inferior as demais, as quais foram de $(0,1979$ e $0,5088 \%)$.

Perdas estimadas de forma indireta: Processo respiratório das sementes

Para o teste realizado de perda de peso provocada pelo processo respiratório os fatores, tipo de embalagem, mostraram efeito significativo, períodos de avaliação mostraram efeito altamente significativo e o fator de temperatura de secagem não mostrou efeito significativo. Na Figura 5 pode-se observar que a perda de peso dos grãos devido à atividade respiratória foi mais elevada significativamente no período de oito meses de armazenamento, independentemente da temperatura de secagem utilizada nos grãos armazenados em embalagem de papel. As médias da perda de peso nesse período não diferiram entre si. Observa-se ainda, na Figura 5 que as perdas de peso em dois, quatro e seis meses de armazenamento foram praticamente iguais, não diferindo entre si significativamente na embalagem de papel.

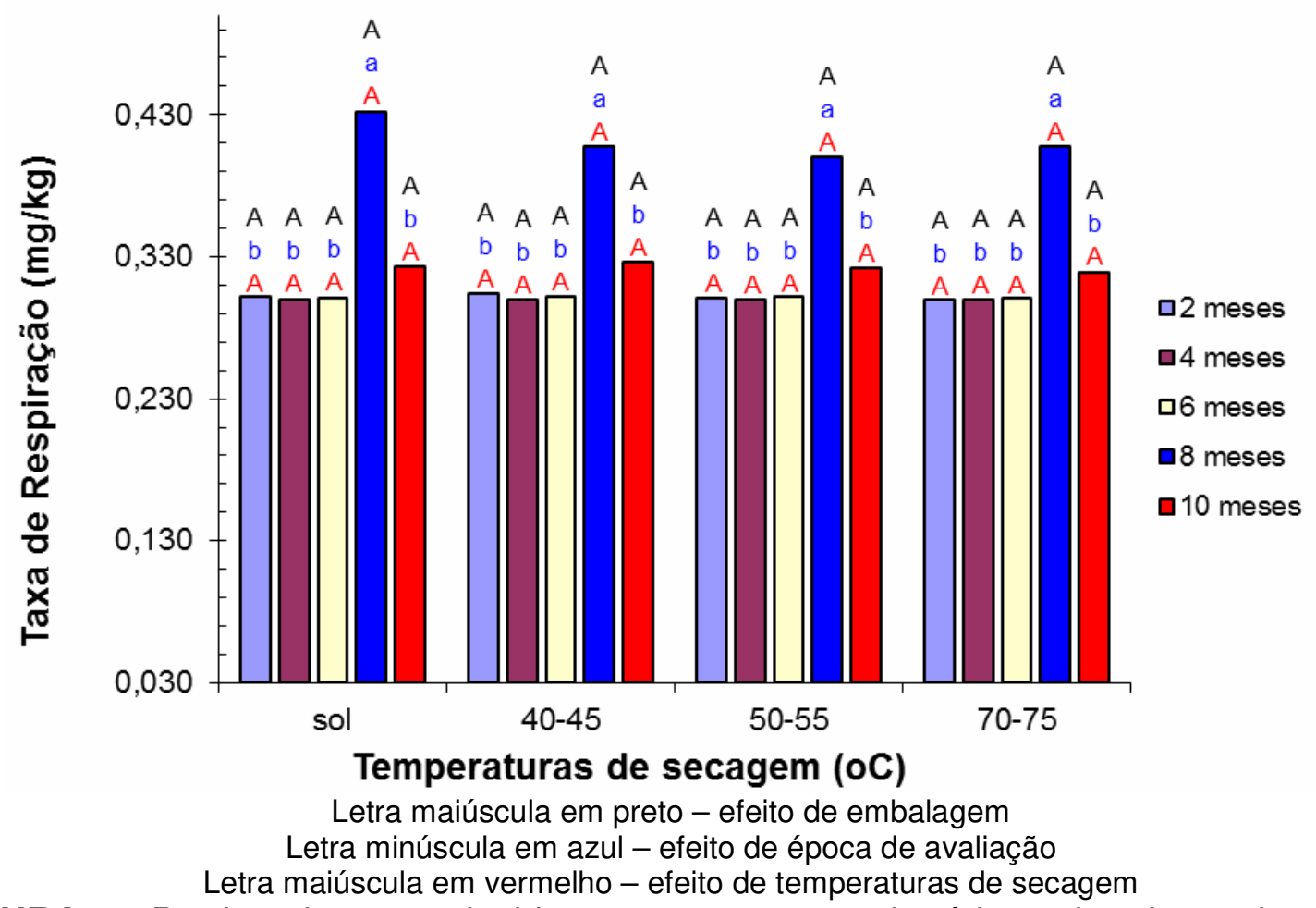

FIGURA 5. Perdas de peso devido ao processo respiratório estimadas pelo método do Bern et al. (2002) em embalagem de papel.

As perdas constatadas na Figura 5 determinadas pelo método de Bern et al. (2002) foram em média 0,412 $\mathrm{mg} \mathrm{CO}$. $\mathrm{kg}^{-1}$ corresponde a $0,03 \%$ de perda de ENCICLOPÉDIA BIOSFERA, Centro Científico Conhecer - Goiânia, v.14 n.26; p.264 
matéria seca no período de oito meses e $0,302 \mathrm{mg} \mathrm{CO} \cdot \mathrm{kg}^{-1}$ e $0,323 \mathrm{mg} \mathrm{CO}$. $\mathrm{kg}^{-1}$ correspondem a $0,02 \%$ de perda de matéria seca, respectivamente, para dois, quatro e seis e dez meses de armazenamento. Esses resultados de perda matéria seca devido à produção de $\mathrm{CO}_{2}$ foram bem menores ao encontrado por Wilcke et al. (1993) em estudo executado com grãos de milho. Em estudo realizado com grãos de milho por Eira e Biaggioni, (2014) encontraram que a perda de matéria seca, na qual se encontra expurgada a variação de peso devido à remoção de água durante a secagem, resultou em uma quebra técnica significativa em todos os tratamentos de secagem, sugerindo um efeito imediato da operação de secagem sobre a qualidade dos grãos. Na Figura 5 os grãos armazenados em embalagens de papel, ocasionam médias de perda que não diferiram entre si significativamente para os efeitos dos fatores de época de avaliação e temperaturas de secagem.

$\mathrm{Na}$ Figura 6 pode-se observar que a perda de peso dos grãos devido à atividade respiratória foi mais elevada de forma significativa no período de oito meses de armazenamento, independentemente da temperatura de secagem utilizada nos grãos armazenados em embalagem de plástico. Neste período, as médias de perda de peso diferiram entre si. Segundo Carvalho e Nakagawa (2012), umidade relativa do ar tem relação direta com o teor de umidade das sementes, além de controlar a ocorrência dos diferentes processos metabólicos que ela pode sofrer, principalmente a degradação das reservas com o aumento da atividade respiratória, como a embalagem de plástico tem permeabilidade diferente da embalagem de papel o resultado corrobora com a afirmação dos autores.

Observa-se ainda, na Figura 6 que as perdas de peso em dois, quatro e seis meses de armazenamento foram praticamente iguais, não diferindo entre si, significativamente na embalagem de plástico. As perdas constatadas na Figura 6 determinadas pelo método do Bern et al. (2002) foram em média $0,351 \mathrm{mg} \mathrm{CO}$. $\mathrm{kg}^{-1}$ correspondente a $0,02 \%$ de perda de matéria seca no período de oito meses e 0,301 $\mathrm{mg} \mathrm{CO} 2 . \mathrm{kg}^{-1}$ e $0,314 \mathrm{mg} \mathrm{CO} 2 . \mathrm{kg}^{-1}$, respectivamente, para dois, quatro e seis e dez meses de armazenamento, correspondendo a mesma perda de matéria seca no período de oito meses. 


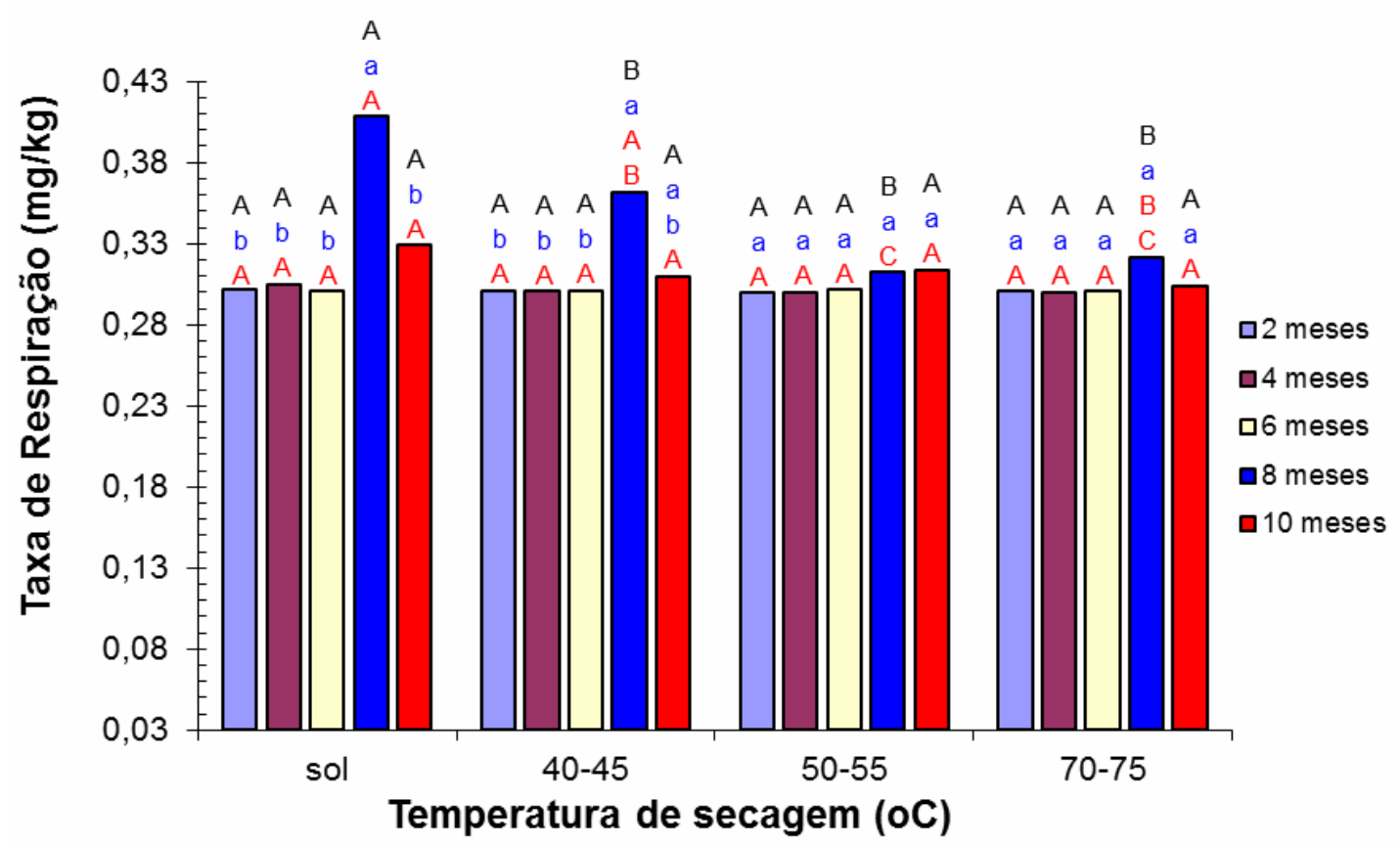

Letra maiúscula em preto - efeito de embalagem Letra minúscula em azul - efeito de época de avaliação Letra maiúscula em vermelho - efeito de temperaturas de secagem

FIGURA 6. Perdas de peso devido ao processo respiratório estimadas pelo método do Bern et al. (2002) em embalagem de plástico.

Na Figura 6 verifica-se que nos grãos armazenados em embalagens de plástico, em relação ao efeito fator época de avaliação nas médias de perda de peso provocadas pelo processo respiratório dos grãos para os tratamentos de secagem ao sol e a $40-45^{\circ} \mathrm{C}$ não diferiram entre si, porém diferiram dos demais tratamentos de secagem. No período de oito meses de armazenamento a umidade dos grãos armazenados, foi mais elevada, resultando numa taxa de produção de $\mathrm{CO}_{2}$ elevada ocasionada pelo aumento do teor de água dos grãos de milho.

De acordo com Costa et al. (2013) durante a recepção de grãos, o teor de água do milho é um parâmetro de extrema importância e pode variar conforme muitos fatores relacionados ao meio. $O$ teor de água dos grãos é o fator mais importante que afeta a taxa de respiração, e a mesma aumenta exponencialmente com a elevação do teor de água. O teor de água nesse período, foi em média de $11,58 \%$, em que corresponde a uma liberação pela taxa de respiração de $0,0127 \mathrm{~mL} \mathrm{CO}_{2} . \mathrm{g}$ de peso $\operatorname{seco}^{-1} \cdot \mathrm{dia}^{-1}$. Em dois, quatro, e seis meses de armazenamento o teor de água dos grãos foi em média de 8-9\% em que corresponde a uma liberação pela taxa de respiração de $0,0009 \mathrm{~mL} \mathrm{CO}$.g de peso seco-1.dia ${ }^{-1}$. Resultados que corroboram com Marini et al., (2013) em que dados encontrados mostram que taxa respiratória das sementes de arroz aumentou de forma exponencial à medida que aumentou a temperatura de exposição das sementes.

Para o teste realizado de perda de peso provocada pelo processo respiratório os fatores, o tipo de embalagem e fator temperatura, não mostraram efeito significativo, já os períodos de avaliação mostraram efeito altamente significativo. $\mathrm{Na}$ Figura 7 pode-se observar que a perda de peso dos grãos devido à atividade ENCICLOPÉDIA BIOSFERA, Centro Científico Conhecer - Goiânia, v.14 n.26; p.266 2017 
respiratória foi mais elevada de forma altamente significativa no período de 10 meses de armazenamento, independentemente da temperatura de secagem utilizada nos grãos armazenados em embalagem de papel. Neste período, as médias da perda de peso não diferiram entre si.

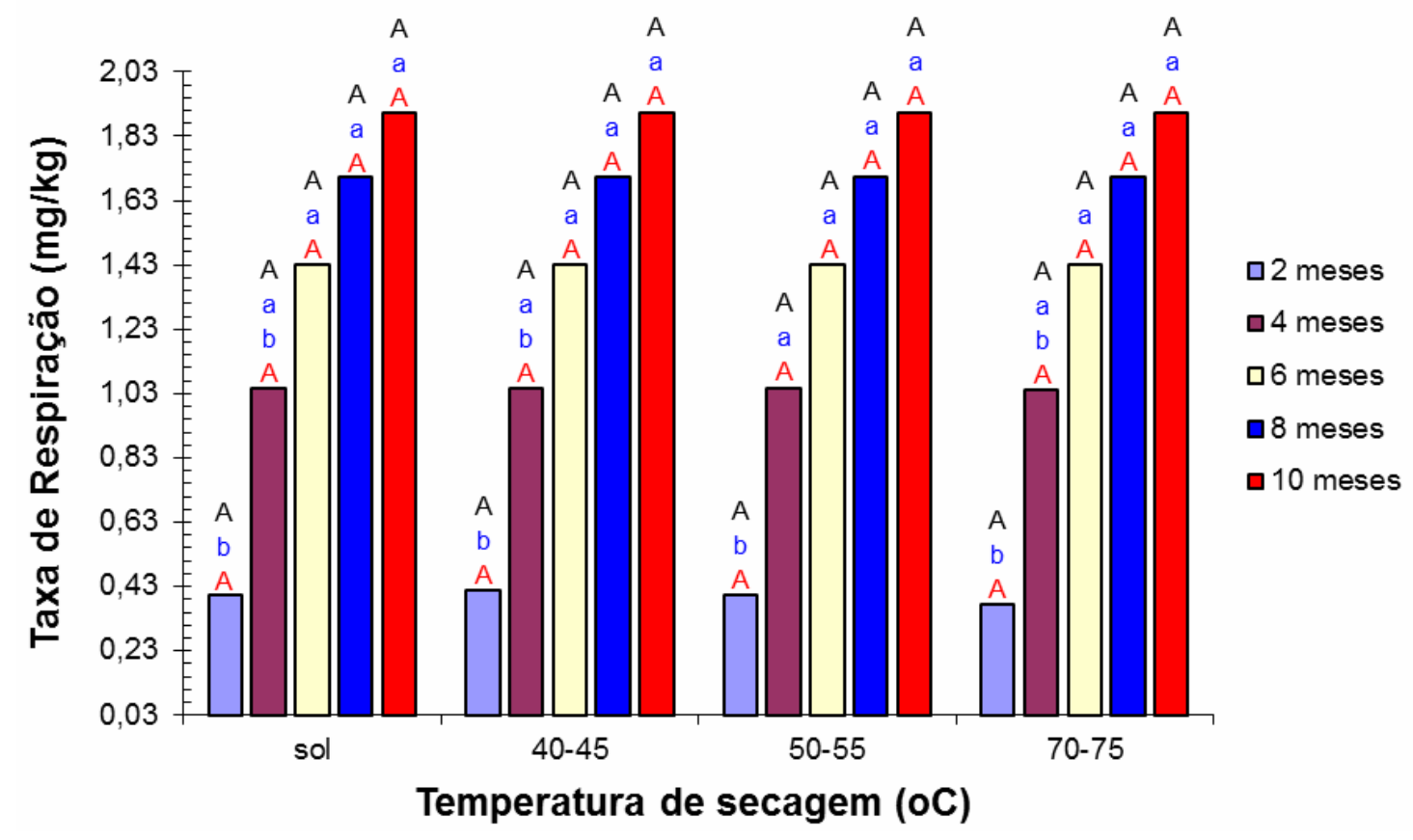

Letra maiúscula em preto - efeito de embalagem Letra minúscula em azul - efeito de época de avaliação Letra maiúscula em vermelho - efeito de temperaturas de secagem

FIGURA 7. Perdas de peso devido ao processo respiratório estimadas pelo método do White et al. (1982) em embalagem de papel.

Na Figura 7 observa-se ainda, que a perda de peso dos grãos de milho devido ao processo respiratório aumenta linearmente de forma proporcional a cada período de armazenamento dos grãos, independentemente da temperatura de secagem utilizada. O processo respiratório foi observado em estudos realizados com o vigor das sementes por Aumonde et al., (2012) que observaram maior atividade respiratória em lotes de maior vigor.

$\mathrm{Na}$ Figura 8, praticamente não houve diferenças nos resultados das perdas de peso dos grãos armazenados em embalagem de plástico, quando comparado aos resultados constatados na Figura 7. No entanto, para o efeito fator época ocorreram diferenças entre si nas médias de perda de peso nos grãos armazenados em embalagem de plástico, sendo que, em seis e oito meses não houve diferença, resultado constatado para o tratamento de secagem ao sol. 


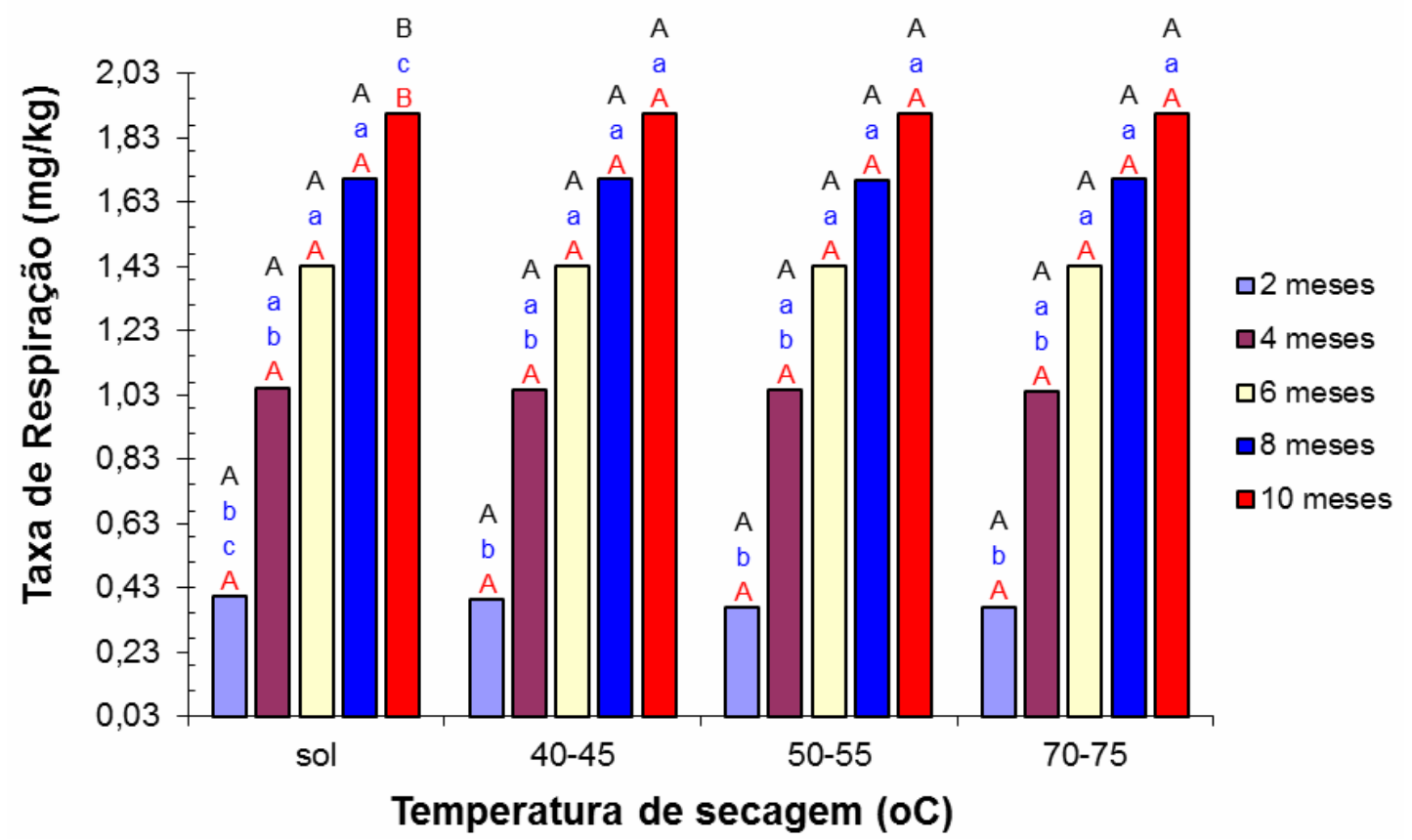

Letra maiúscula em preto - efeito de embalagem Letra minúscula em azul - efeito de época de avaliação Letra maiúscula em vermelho - efeito de temperaturas de secagem

FIGURA 8. Perdas de peso devido ao processo respiratório estimadas pelo método do White et al. (1982) em embalagem de plástico.

Verifica-se que neste método de White et al. (1982), praticamente não foi detectado diferenças nas médias das perdas de peso devido ao processo respiratório dos grãos armazenados em embalagens de papel e plástico. Devido aos resultados encontrados, deve-se aprimorá-lo, pois o mesmo não considera os dados de danificação nos grãos, seja por insetos ou fungos, os quais tem grande participação ativa na taxa de respiração dos grãos, característica esta, que o método do Bern et al. (2002) considera. No entanto, o método do White et al. (1982) é um método de estimar perda de peso devido o processo respiratório com certa confiabilidade, pois os dados obtidos de perdas de peso conforme as Figuras 7 e 8 foram próximos aos dados obtidos utilizando os métodos de determinação direta. E a linearidade dos dados, mostrando que à medida que havia um prolongamento do período de armazenamento $\mathrm{a}$ perda de peso das amostras armazenadas em embalagens de papel e plástico aumentavam conforme o período, devido à taxa de respiração. $\mathrm{O}$ que se observa na prática é exatamente esse tipo de comportamento no produto que está armazenado o que tem como referência à "Quebra técnica".

\section{CONCLUSÕES}

As perdas de peso mais elevadas foram constatadas no método do Compton et al. (1998). O método indireto do White et al. (1982) foi mais confiável devido à proporcionalidade da perda em relação ao período de armazenamento. No geral o tratamento de secagem ao sol foi o que mais influenciou negativamente a perda de peso dos grãos. As embalagens de papel e plástico não teve efeito significativo quando 
utilizou-se o método do Harris e Lindblad (1978) e do White et al. (1982) na determinação da perda.

\section{REFERÊNCIAS}

AUMONDE T.Z; MARINI P; MORAES D.M; MAIA M.S; PEDÓ T; TILLMANN M.A.A; VILLELA F.A. Classificação do vigor de sementes de feijão miúdo pela atividade respiratória. Revista Interciência, 37: 55-58. 2012Disponível em: <http://www.producao.usp.br/handle/BDPI/42205> Acesso em: 24. set/2017.

BAUDET, L.M. \& VILLELA, F.A. Armazenamento. Seed News, Pelotas, v.4, n.4, p.28$32,2000$.

BERN, C.J.; STEELE, J.L.; MOREY, R.V. Shelled com $\mathrm{CO}_{2}$ evolution and storage time for $0,5 \%$ dry matter loss. Applied Engineering in agriculture, v.18, n.6, p.703-706, 2002.

CARDOSO, R. B.; BINOTTI, F. F. da S.; CARDOSO, E. D. Potencial fisiológico de sementes de crambe em função de embalagens e armazenamento. Pesquisa Agropecuária Tropical, v.42, p.272-278, 2012.Disponível em: <http://dx.doi.org/10.1590/S1983-40632012000300006> .doi 10.1590/S198340632012000300006.

CARVALHO, N. M.; NAKAGAWA, J. Sementes: ciência, tecnologia e produção. 5.ed. FUNEP: Jaboticabal, 2012. 590p

COMPTON, J.A.F. Reducing losses in small farm grain storage in the tropics. 1992, Chatham:RL. Disponível em:<http://www.fao.org/docrep.htm/>. Acesso em: 02 ago. 2017.

COMPTON, J.A.F; FLOYD, S.; OFOSU, A.; AGBO, B. The modified count and weight method: and improved procedure for assessing weight loss in stored maize cobs. Journal Stored Product Research, v.34, n.4, p.277-285, 1998.Disponível em: <https://doi.org/10.1016/S0022-474X(98)00009-5>. doi 10.1016/S0022474X(98)00009-5

COSTA, D. M.; MACHADO, L.C.;BITTENCOURT, F.; PEREIRA, L.C.Qualidade do milho para nutrição animal comercializado a varejo e métodos para determinação da umidade. Revista Agrogeoambiental, Pouso Alegre, v. 5, n. 2, caderno I, p. 25-34, ago. 2013. Disponível em: <https://agrogeoambiental.ifsuldeminas.edu.br/index.php/ Agrogeoambiental/article/download/436/481>.Acesso em: 28. Set. 2017.

EIRAS, D.L.;BIAGIONNI, M.A.M. Perda de matéria seca em grãos de milho submetidos a sistemas de secagem natural e artificial. Revista Energia na Agricultura. Energ. Agric., Botucatu, vol. 29, n.3, p.228-235, julho-setembro, 2014. Disponível em: http://revistas.fca.unesp.br/index.php/energia/article/viewFile/843/pdf-ISSN: 1808-8759. 
GUPTA, P.; WILCKE, W.F.; MOREY, R.V.; MERONUCK, R.A. Effect of dry matter loss on corn quality. ASAE Annual International Meeting. Orlando: ASAE, 1998. (Paper, 98-6042).

HARRIS, K.L.; LINDBLAD, C.J. Postharvest grain loss assessment methods. Minneapoles: Am. Assoc. Cereal Chem., 1978. 193 p.

MARINI, P.; MORAES, C.L; LARRÉ, C.F;LIMA, M.C;MORAES, D.M; AMARANTE, L. Indicativos da perda de qualidade de sementes de arroz sob diferentes temperaturas através da atividade enzimática e respiratória.2013, V. 38; N.1. Sistema de Científica. Disponível em:

http://www.redalyc.org/revista.oa?id=339>.Acesso em: 24. set/ 2017.

POMERANZ, Y. Biochemical, functional, and nutritive changes during storage. In: SAUER, D.B. (Ed.). Storage of cereal grains and their products. 4. ed. St. Paul: American Association Cereal Chemistry, 1992.

SANTOS, S.B; MARTINS, M.A; FARONI, L.R.DA; BRITO JUNIOR,V.R. Perda de matéria seca em grãos de milho armazenados em bolsas herméticas. Revista Ciência Agronômica, v. 43, n. 4, p. 674-682, out-dez, 2012.

WHITE, N.D.G.; SINHA, R.N.; MUIR, W.E. Intergranular carbon dioxide as an indicator of deterioration in stored rapeseed. Canadian Agricultural Engineering, v.24, n.1, p.43-49, 1982a.

WILCKE, W.F.; MERONUCK, R.A.; MOREY, R.V.; NG, H.F.; LANG, J.P.; JIANG, D. Storage life of shelled corn treated with a fungicide. Transactions of the ASAE, v.36, p.1847-1854, 1993. 